\title{
Violência contra a mulher no contexto escolar: ações pedagógicas como instrumento de sensibilização contra o feminicídio no Estado do Amazonas/Brasil
}

\author{
Violence against women in the school context: pedagogical actions as a tool to raise awareness \\ against feminicide in the State of Amazonas/Brazil
}

La violencia contra las mujeres en el contexto escolar: acciones pedagógicas como herramienta de sensibilización contra el feminicidio en el Estado de Amazonas/Brasil

\section{Resumo}

O presente artigo discorre sobre ações pedagógicas como instrumento de sensibilização contra o feminicídio. Trata-se de um recorte de pesquisa em andamento desenvolvida no Programa de Pós-Graduação em Ensino de Ciências e Humanidades (PPGECH) no âmbito da Universidade Federal do Amazonas - UFAM, Unidade de Humaitá - IEAA, cujo foco é pensar, no âmbito escolar, as questões em torno da violência de gênero como possibilidade de sensibilização acerca do feminicídio no Estado do Amazonas. Para isso, fez-se necessário: contextualizar o quadro atual de violência de gênero e feminicídio no Estado do Amazonas; olhar as orientações sugeridas pela Secretaria de Estado de Educação do Amazonas em relação à abordagem dessa temática na escola e questionar os impactos das práticas voltadas ao combate ao feminicídio realizadas no ambiente escolar. O amparo teórico-metodológico inspirouse nos estudos pós-críticos em educação. Os dados foram produzidos a partir de uma pesquisa bibliográfica e documental. Os principais resultados alcançados sugerem que é de extrema relevância pensar a escola como palco de discussões das questões de violência escolar no estado do Amazonas, visto que os casos de feminicídio têm crescido consideravelmente, inclusive nesses tempos de pandemia.

Palavras-chave: Violência; Feminicídio; Mulher; Gênero; Educação.

\begin{abstract}
The present article discusses pedagogical actions as a tool to raise awareness against feminicide. It is a part of an ongoing research developed in the Graduate Program in Teaching of Sciences and Humanities (PPGECH) in the Federal University of Amazonas - UFAM, Humaitá Unit - IEAA, whose focus is to think, in the school environment, the issues around gender violence as a possibility of awareness about feminicide in the State of Amazonas. For this, it was necessary: to contextualize the current picture of gender violence and feminicide in the State of Amazonas; to look at the guidelines suggested by the State Department of Education of Amazonas regarding the approach of this theme at school and to question the impacts of the practices aimed at fighting feminicide carried out in the school environment. The theoretical and methodological support was inspired by post-critical studies in education. The data were produced from a bibliographic and documental research. The main results suggest that it is extremely important to think of the school as a stage for discussing issues of school violence in the state of Amazonas, since cases of feminicide have grown considerably, including in these times of pandemic.
\end{abstract}

Keywords: Violence; Feminicide; Woman; Gender; Education.

\section{Resumen}

El presente artículo aborda las acciones pedagógicas como herramienta de sensibilización contra el feminicidio. Se trata de una investigación en curso desarrollada en el Programa de Posgrado en Enseñanza de las Ciencias y Humanidades (PPGECH) en la Universidad Federal de Amazonas - UFAM, Unidad de Humaitá - IEAA, cuyo enfoque es pensar, en el ámbito escolar, las cuestiones en torno a la violencia de género como una posibilidad de sensibilización sobre el feminicidio en el Estado de Amazonas. Para eso, fue necesario: contextualizar el cuadro actual de la violencia de género y del feminicidio en el Estado de Amazonas; mirar las orientaciones sugeridas por la Secretaría de Estado de Educación de Amazonas en relación al abordaje de esa temática en la escuela y cuestionar los 
impactos de las prácticas dirigidas al combate al feminicidio realizadas en el ambiente escolar. El soporte teórico y metodológico se inspiró en los estudios post-críticos en educación. Los datos se produjeron a partir de una investigación bibliográfica y documental. Los principales resultados alcanzados sugieren que es extremadamente relevante pensar en la escuela como escenario para la discusión de los temas de violencia escolar en el estado de Amazonas, ya que los casos de feminicidio han crecido considerablemente, incluso en estos tiempos de pandemia.

Palabras clave: Violencia; Feminicidio; Mujer; Género; Educación.

\section{Considerações Iniciais}

Abordar a violência contra mulher engloba a inclusão de diversos aspectos na pauta da discussão, visto se tratar de um problema que envolve questões políticas, sociais, culturais e de gênero. No presente texto, o tema será discutido a partir do contexto escolar e pensado como instrumento de sensibilização contra o feminicídio.

O ponto de partida das discussões está embasado no questionamento norteador da pesquisa: Qual a importância de se abordar no contexto escolar a questão da violência de gênero, como forma de sensibilização acerca do feminicídio? Alinhado a esse problema investigativo, estabeleceu-se como objetivo geral dessa pesquisa: pensar sobre a relevância da abordagem, no âmbito escolar, das questões em torno da violência de gênero, como possibilidade de sensibilização acerca do feminicídio no Estado do Amazonas.

A fim de alcançar esse propósito fez-se necessário contextualizar o quadro atual de violência de gênero e feminicídio no Estado do Amazonas, bem como olhar as orientações sugeridas pela Secretaria de Estado de Educação do Amazonas em relação à abordagem dessa temática na escola e questionar os impactos das práticas voltadas ao combate ao feminicídio, realizadas no ambiente escolar.

O amparo teórico-metodológico inspirou-se nos estudos pós-críticos em educação, a partir do que propõem Meyer e Paraíso (2012). Segundo as autoras, os temas ligados às questões de gênero, como o feminicídio, requerem um olhar desprendido que assegure construir outras perguntas e outros pensamentos, visando se afastar "daquilo que é rígido, das essências, das convicções universais, da tarefa de prescrever e de todos os conceitos que não ajudam a construir imagem de pensamentos potentes para descrever e analisar nosso objeto" (p.18-19).

Os verbos pensar, olhar, contextualizar e questionar são utilizados a partir das definições propostas por Fonseca, Nascimento e Maraschin (2012, p. 09), na obra Pesquisar na Diferença, as quais apresentam novas nuances a esses termos, "não se trataria, portanto, de considerar cada ação como portadora de um único sentido. Os procedimentos demarcados por verbos no infinitivo nos forçam a pensar haver diversos modos de usá-los".

Os dados foram produzidos a partir de uma pesquisa bibliográfica e documental. Os dados bibliográficos foram construídos a partir de pesquisas recentes desenvolvidas em contextos acadêmicos e científicos. Já as ações desenvolvidas pela Secretaria de Estado e Educação foram extraídas de documentos públicos, disponibilizados pela própria secretaria em sites oficiais da SEDUC/AM e do Governo do Estado do Amazonas.

A abordagem utilizada é qualitativa, a partir das reflexões de Gastaldo (2018, p.10), a qual afirma que a pesquisa qualitativa, sob a ótica pós-crítica, procura "explorar modos alternativos de pensar, falar e potencialmente fazer determinadas práticas sociais e, concomitantemente, remodelar as metodologias de pesquisa, para que elas não se constituam como ferramentas de reprodução social".

As discussões se deram no contexto do Estado do Amazonas, frente aos casos de violência contra a mulher, destacando o contexto escolar. Espera-se, desse modo, contribuir para a sensibilização em relação à necessidade de utilizar as diversas possibilidades formativas para combater as práticas de violência e feminicídio na sociedade amazonense e brasileira, de forma geral. 


\section{Amparo Teórico-Metodológico}

As escolhas metodológicas de uma pesquisa ocupam um ponto de atenção na hora de planejá-la, visto que, conforme Meyer e Paraíso (2012), toda metodologia é pedagógica e se refere às questões sobre como fazer e proceder em determinado contexto sociocultural. Essa forma de conduzir a pesquisa deve levar em consideração a temática a ser desenvolvida, os atores e sujeitos envolvidos. Como o objeto dessa pesquisa é voltado a questionamentos de gênero, isto por abordar a violência contra a mulher no Amazonas/Brasil, tema ainda tópico de discussões confrontáveis em alguns cenários, inclusive nos contextos escolares, ele requer uma estratégia de pesquisa flexível, como indicam os estudos pós-críticos.

Em articulação ao campo pós-crítico, Candau (2020) aponta que a perspectiva cultural tem se afirmado no contexto social e educacional e tem promovido uma nova sensibilidade à temática de gênero no contexto escolar, de modo a promover o reconhecimento e valorização das diferenças de gênero e sexualidade, étnico-raciais, religiosas, entre outras. No entanto, a autora questiona se as ações desenvolvidas no cotidiano escolar têm conseguido aprofundar o diálogo entre os sujeitos socioculturais presentes em seu contexto de atuação.

A questão do combate à violência contra a mulher, em suas especificidades, faz parte da pauta dos estudos culturais e feministas, por entender que muitas dessas violências são frutos de uma cultura historicamente dominada por opressões patriarcais, que insistem em definir um papel específico para homens e mulheres.

Este enquadramento permite questionar algumas das formas que a violência sobre as mulheres pode assumir quer no espaço público (que também é familiar) quer no espaço familiar (que também é público). Partindo da múltipla interpelação e frequente replicabilidade das relações de poder inerentes a estes espaços, acentuo como a violência não é apenas contra as mulheres, mas também sobre elas, na medida em que nos situa em posições de subordinação, desvalorização e falta de reconhecimento. (Brabo, 2015, p. 07).

Nesse contexto, é importante entender algumas considerações sobre o movimento feminista. Vale pontuar que o feminismo representa uma espécie de busca das mulheres pela liberdade de sua condição de oprimida e subjugada, em direção a um status de igualdade, valorização e respeito, capaz de superar as limitações historicamente impostas à existência da mulher. Assim, é preciso acentuar que o feminismo não é o oposto de machismo, sua busca não é promover o ódio aos homens, não visa combatê-los, mas visa ultrapassar os papéis atribuídos a homens e mulheres, combater as práticas machistas e os comportamentos sexistas da sociedade.

Figueiredo e Martins (2020, p. 335) defendem que o feminismo representa um movimento que vai além do social, visto ser também um movimento político, que discute, dentre outros pontos, "a desconstrução dos padrões machistas de uma sociedade patriarcal [...] sua base política deve ser antirracista, combatente da LGBTfobia e as diferentes formas de opressão que recaem sobre os grupos socialmente excluídos".

A partir desse entendimento, faz-se necessário rever conceitos e definições de alguns pontos importantes da investigação. Um exemplo disso, diz respeito à escolha dos verbos utilizados na construção da pesquisa. Ao se estabelecer como objetivo da investigação "pensar" sobre a violência contra a mulher no contexto escolar, remete-se ao que propõe Lemos e Rocha (2012, p. 181) ao afirmarem que "pensar se constitui em um ato criativo produzido na perturbação que os arranjos produzidos sofrem quando não mais conseguem sustentar um território existencial”.

Ou seja, é urgente pensar sobre os aspectos que impactam ou motivam os insistentes índices de registros de violência contra a mulher, de modo que se promova uma perturbação inquietante diante deste cenário que não pode mais ser tolerado de forma passiva. A escola como cenário de reflexões e provocações, deve estar inserida nesse processo de pensar alternativas de sensibilização e combate. 
"Olhar", como objetivo de pesquisa, está relacionado ao que Zanela (2012, p. 169) define, sob uma perspectiva de "ver não como atividade do olho nu, esse uma quimera, mas de um olhar social e historicamente produzido que entrevê não o real em si, mas este sob o prisma de sua refração". Sendo assim, não se trata apenas de descrever números ou apontar falhas, mas de buscar propostas que possibilitem uma mudança de cenário.

De igual modo, contextualizar e questionar vão além do que propõem os mais célebres dicionários da língua portuguesa. Trata-se de contextualizar como operação de visibilizar as possíveis relações de uma organização com o seu entorno, evidenciando as ocorrências de tempo e espaço que afetaram e afetam um determinado objeto ou sujeito. (Costa, 2012). Já o verbo questionar, a partir do que propõe Batista (2012), reflete o ato de pesquisar, visto que o pesquisador expressa a vontade de perscrutar a realidade, o que foi construído socialmente e cristalizado como verdade. Desse modo,

Questionar é sair também do seu campo metodológico e embrenhar-se em saberes alinhados: as ciências humanas e sociais são fundamentalmente porosas, são trans. Literatura, geografia, história, psicologia, sociologia, filosofia, comunicação: questionar é também espraiar e combinar novos fazeres na aventura metodológica. Com rigor, mas sem perder a imaginação jamais. (Batista, 2012, p. 199).

Postas essas observações importantes, vale destacar que os estudos pós-críticos em educação se inspiram em algumas abordagens teóricas fundamentais, geralmente conhecidas pelos prefixos "pós", como pós-estruturalismo, pós-modernismo, pós-colonialismo, pós-feminismo, assim como os estudos culturais, o multiculturalismo e estudos de gênero, os quais dialogam de forma fraterna com a abordagem em estudo (Meyer \& Paraíso, 2012).

A partir dessas bases teóricas, entende-se que seja possível, pensar sobre os fatores que influenciam essa crescente demanda em torno da violência contra a mulher, visto que essa sensibilização é fundamental para que a sociedade entenda as consequências que podem ser vivenciadas, caso esse enfrentamento não ocorra nas instituições basilares, como a escola, por exemplo.

\section{Resultados e Discussão}

Abordar a temática sobre a violência contra a mulher pode parecer um desgaste para alguns estudiosos, mas jamais o será para quem sofreu ou sofre algum tipo de violência. A violência contra a mulher tende a ser o resultado de uma relação complexa que envolve cultura, relacionamento, contexto e sociedade (Almeida, 2019). É fundamental entender que esse tipo de violência está diretamente relacionado à determinação social dos papeis masculino e feminino, pois

Toda sociedade pode atribuir diferentes papeis ao homem e a mulher. Até aí tudo bem. Isso todavia, adquire caráter discriminatório quando a tais papeis são estabelecidos pesos e importâncias diferenciados. Quando a valoração social desses papeis é distinta, há desequilíbrio, assimetria nas relações sociais, o que pode acarretar violência. No caso da nossa sociedade, os papeis masculinos são supervalorizados em detrimento dos femininos, trazendo prejuízos para as mulheres que, em sua dimensão mais acentuada, chegam à violência contra a mulher. (Bianchini; Bazzo; Chakian, 2021, p. 20).

Segundo Gomes (2020, p. 121) "o patriarcado está presente na sociedade e fundamenta-se na distinção social entre os sexos biológicos e manifesta-se na forma de inferiorizarão da mulher em relação ao homem. As relações de poder e manifestação do patriarcado que mais atinge as mulheres é a violência”. A autora defende que a violência contra a mulher é fruto da sociedade patriarcal, com características complexas e multifacetadas.

Rios et al., (2019, p. 40) destacam ser "comum que o agressor culpe a vítima pelo seu próprio assassinato, seja pela forma como ela se veste, seja por ela assumir uma conduta mais independente ao tentar trabalhar ou estudar, ou, muito frequentemente, por desejar romper o relacionamento ou envolver-se com um novo parceiro". 
As inúmeras mudanças ocorridas ao longo dos anos, no que se refere aos papeis culturalmente estabelecidos para homens e mulheres, têm gerado um amplo debate acerca dos novos posicionamentos sociais das mulheres e, consequentemente, dos homens, os quais, por vezes, não aceitam as novas conjunturas de empoderamento da mulher. Bianchini, Bazo e Chakian (2021) afirmam que o desequilíbrio de poder entre os sexos é tão desproporcional que manifesta uma hierarquia autoritária, sem espaço para interdependência. Elas destacam que o homem sente-se legitimado a fazer uso da violência, o que também pode explicar, em alguns casos, a inércia da mulher, que acaba se reconciliando com o agressor, mesmo após repetidos episódios de violência, assim

Corrobora essa afirmativa a pesquisa da Fundação Perseu Abramo indicando que não é incomum as mulheres sofrerem agressões físicas por parte do companheiro por mais de dez anos. Em relação a esse fato, diversos estudos demonstram que tal submissão decorre de condições concretas (físicas, psicológicas, sociais e econômicas) a que a mulher se encontra submetida/enredada, exatamente por conta do papel social que lhe é atribuído socialmente. (Bianchini; Bazzo; Chakian, 2021, p. 20).

É importante salientar que muitos homens se veem envolvidos em uma redoma de misoginia, que os levam a consolidar cada vez mais as desigualdades entre homens e mulheres. Almeida $(2019$, p. 17) entende misoginia como "uma palavra, ação ou comportamento que envolve desconfiança, desprezo ou ódio pela mulher ou qualquer outra questão relacionada ao feminino". Acompanhada a essa inferioridade atribuída à mulher, surgem ideias depreciativas e a aparente tolerância às violências físicas e morais praticadas por homens, as quais têm como manifestação suprema, o estupro e o feminicídio (Almeida, 2019). Assim,

As práticas sociais, o comportamento e a mentalidade predominantes ao longo da história que buscaram justificar ou naturalizar a violência contra a mulher acarretaram a inferiorização social dessa mulher. Essa subordinação ao sexo masculino foi então construída historicamente, mas acabou se impondo como uma verdade. (Almeida, 2019, p. 19).

A Lei Maria da Penha, em seu artigo $5^{\circ}$, considera a violência doméstica e familiar contra a mulher “.... qualquer ação ou omissão baseada no gênero que lhe cause morte, lesão, sofrimento físico, sexual e psicológico e dano moral ou patrimonial" (Brasil, 2006, p. 01). Ela pode se manifestar de forma silenciosa ou agressiva, sendo necessário classificar os tipos de violência às quais as mulheres podem ser submetidas, a fim de reconhecerem situações perigosas em casa ou com amigas próximas ou distantes. Almeida (2019) registra ao menos cinco tipos ou formas diferentes de violência: psicológica, moral, patrimonial, sexual e violência física.

Segundo a autora, a violência psicológica está relacionada a atitudes que causem danos emocionais a mulher, geralmente provocados por conta de depreciação de sua condição física, humilhação através de palavras, vigilância exacerbada, violação de intimidade, ridicularização, entre outros. Já a violência moral está mais associada a questões como calúnia, difamação e injúria.

Ao se referir à violência patrimonial, Almeida (2019) define como qualquer ação que se associe a ato de reter, subtrair ou destruir instrumentos de trabalho, bens, valores ou qualquer recurso econômico, quer seja de forma parcial ou total. As violências sexuais e/ou físicas são comumente mais notificadas. Registra-se, pois, que a

Violência sexual consiste em obrigar a mulher a presenciar, manter ou participar de relação sexual não desejada mediante intimidação, ameaça, manipulação, coação ou uso da força, assim como induzi-la a comercializar ou a utilizar sua sexualidade de qualquer modo. (Almeida, 2019, p. 43).

A violência física, por sua vez, pode ocorrer sob diversas manifestações, ou seja, qualquer ação intencional que proporcione risco ou venha causar dano à integridade física da pessoa. Almeida (2019) afirma que a cada 10 mulheres vítimas 
de feminicídio, 07 possuíam histórico recorrente de violência física, ou seja, a autora destaca que a chance da violência física evoluir para um feminicídio é muito grande.

É importante definir o termo feminicídio, assim, Bianchini et al., (2021) destacam que até pouco tempo o feminicídio era considerado crime passional, praticado em contexto de amor e paixão e que só passou a ocupar posição de preocupação na legislação penal do Brasil a partir de 2015. Dentre suas diversas definições, Almeida (2019) também aponta que o feminicídio é a expressão máxima da violência ou a última etapa desse processo violento, considerando a cultura da dominação masculina e da desigualdade nas relações de poder. Rios, Magalhães e Telles (2019, p. 40) afirmam que "no Brasil, o perfil epidemiológico das mulheres vítimas de homicídio é predominantemente de jovens (18 a 30 anos), negras (aumento de 190,9\% de homicídios em 10 anos), agredidas por familiar direto, mortas no próprio domicílio e com predomínio do uso da força na produção das lesões fatais".

Diante dos elevados índices de violência contra a mulher registrados no Brasil e na tentativa de coibir tais práticas, foi aprovada, em 2006, a Lei Maria da Penha, que tem sido considerada um divisor de águas, a fim de legitimizar a luta dos movimentos feministas que há anos denunciam a violência praticada contra mulheres em todo o país. Rios et al., (2019, p. 41) entendem que "a mudança na legislação é um avanço positivo e, juntamente com medidas protetivas nas áreas de saúde e segurança públicas, poderá proporcionar às futuras gerações uma sociedade em que as diferenças de gênero sejam respeitadas, sem o exercício deletério de poder entre homens e mulheres".

\subsection{Violência contra mulher e feminicídio no Estado do Amazonas}

No Estado do Amazonas foi criado um pacto que articula instituições e serviços governamentais, denominada Rede de enfrentamento à violência contra a mulher. Dentre os principais serviços oferecidos, pode-se destacar: juizados especiais de violência doméstica, serviços de saúde voltados aos casos de violência, central de atendimento à mulher, posto de atendimento humanizado, núcleo de atendimento à mulher e rondas especializadas das polícias civil e militar. Ainda assim,

Vários são os questionamentos que circundam a atuação do Estado frente à problemática da violência fatal praticada contra as mulheres no âmbito das relações domésticas/afetivas, ou mesmo fora dela, mas por menosprezo, raiva ou ódio a condição do sexo feminino. Dúvidas surgem quanto à eficácia da Lei 13.104/2015 que inseriu a qualificadora no crime de homicídio, e ainda, sobre as heranças culturais, sociais e morais que perpetuam ao longo dos tempos, permitindo a repetição de comportamentos humanos possessivos e agressivos contra as mulheres até hoje. (Antunes; Fávero, 2019, p. 19).

O documento Diagnóstico de Gênero no Amazonas: políticas públicas e Inclusão de Mulheres (2020), publicado pela Fundação Amazonas Sustentável, órgão mantido pelo Governo do Amazonas ${ }^{1}$ aponta em seu relatório uma pesquisa realizada em 2017, na qual destaca que quase um terço das brasileiras maiores de 16 anos teriam sido vítimas de violência e que apenas um quarto desse quantitativo formalizou denúncia. Assim, no documento citado (p. 37) aparecem informações que mostram "um arcabouço legal abrangente no que diz respeito à violência contra a mulher, ainda se observam altos índices de violência e mortalidade de mulheres".

O mesmo documento, com base em Cerqueira et al (2018 p. 32), cita o Atlas da Violência, levantamento no qual aparecem informações sobre a taxa de feminicídios no Brasil, mostrando que "entre 2006 e 2016 houve um aumento de 6,4\% na taxa de homicídios de mulheres no país. No Amazonas, esse aumento foi de 80,3\%, o sexto maior aumento observado no país. Em 2006 foram mortas 53 mulheres no estado, 10 anos depois, em 2016, esse número saltou para 116 casos no período de 12 meses.

\footnotetext{
${ }^{1}$ Fundação Amazônia Sustentável em https://fas-amazonia.org/publicacao/diagnostico-de-genero-no-amazonas-politicas-publicas-e-inclusao-de-mulheres
} 
Outro dado relevante apresentado no documento mostra que a violência entre mulheres negras é muito maior que entre mulheres brancas e registra que a taxa de homicídios de mulheres negras no Brasil é de 5,3 a cada 100 mil habitantes, enquanto no Amazonas a taxa é de 6,2, para o mesmo número de habitantes. Cerqueira (2020) aponta que, em 2019, 88\% das mulheres mortas no Amazonas eram negras,

Oliveira, Cavalcante e Souza (2020, p. 04) destacam que esses números aumentaram significativamente durante a pandemia. Os casos de feminicídio com maiores destaque englobam estupros, mutilação, venda e troca de mulheres e várias outras agressões que envolvem relações de poder. Os autores destacam, com base em dados do Instituto de Pesquisa Datasenado, que houve "um aumento notável da porcentagem de 13\% para 37\% entre 2011 e 2019 de mulheres agredidas por companheiros [...] laços afetivos para as mulheres dentro de relações heterossexuais nem sempre significam um acolhimento, seguridade ou a possibilidade de existir e ser respeitada como indivíduo com escolhas próprias fora de um sistema de domínio".

Gomes (2020, p. 126) afirma que "a pandemia a Covid-19 escancarou as frágeis políticas de combate à violência contra mulher. Mesmo com o aumento dos casos de violência contra a mulher no mundo durante o isolamento social, não houve o preparo por meio das ações do governo federal para o enfrentamento dessas demandas no Brasil”. Esses dados acentuam a necessidade de uma maior abordagem do tema sobre violência contra a mulher em todos os espaços, inclusive a escola. Apesar de o Estado contar com uma rede de atendimento, envolvendo órgãos de segurança pública, o judiciário, saúde e assistência social, é preciso que haja um maior engajamento dos atores educacionais nesse processo de enfrentamento a violência.

\subsection{O posicionamento da SEDUC/AM quanto às questões de violência contra a mulher}

Ferreira e Neves (2020, p. 55) enfatizam que as implicações que envolvem a violência contra a mulher são complexas e que o problema "não se resolverá de forma simples, já que suas raízes são estruturais e estruturantes de sociedade machista, misógina, patriarcal e sexista. Encontrar estratégias de enfrentamento representa um enorme desafio tanto para as mulheres em geral, como para os demais segmentos da sociedade civil".

A Secretaria de Estado de Educação e Desporto do Amazonas (SEDUC/AM) possui um Departamento de Políticas e Programas Educacionais, responsável por elaborar e alinhar as políticas públicas para a Educação Básica do Estado do Amazonas. Peixoto e Pereira (2021, p. 23) enfatizam que educar "exige conhecimentos prévios, tanto sobre a área de atuação docente, quando das demais, implica a convivência e as relações sociais. Portanto, o/a professor/a precisa estar munido de saberes, assim como reconstruindo seu arsenal, frente às mudanças e exigências sociais que são muito rápidas.

Nessa perspectiva, dentre as ações voltadas ao público feminino, a Gerência de Apoio e Atendimento a Diversidade (GAAED) realiza, anualmente, um concurso de sensibilização e combate à violência contra a mulher. As ações do concurso, cujos resultados encontram-se disponíveis no site oficial da SEDUC/AM ${ }^{2}$, visam estimular a sensibilização em torno da temática, a partir de diálogos, palestras e atividades de música, teatro e redação. O projeto é desenvolvido em parceria com a Secretaria de Estado de Justiça ${ }^{3}$ e premia as melhores ações em cada uma das categorias, movimentando alunos e professores de toda a rede estadual.

Machado e Lima (2021) defendem que a escola se envolva nas questões relacionadas à violência de gênero, posto que os assuntos educacionais precisam de conexão com a realidade social, política, econômica e/ou cultural do seu tempo, visto se tratar de uma organização social, "ela visa à compreensão dos sujeitos da estrutura social ao qual está inserido, o porquê das modificações que nela se processam e auxilia para que estes sejam atuantes do processo social, para assim favorecer a

\footnotetext{
${ }^{2}$ http://www.educacao.am.gov.br/estudantes-da-rede-estadual-discutem-violencia-contra-a-mulher-em-concurso-de-redacao-musica-e-teatro/

${ }^{3}$ http://www.amazonas.am.gov.br/2019/08/governo-do-amazonas-lanca-7-concurso-estadual-sobre-prevencao-a-violencia-contra-as-mulheres/
} 
mudança social ou tomarem um posicionamento contra ela" (Machado \& Lima, 2021, p. 43). A partir desse entendimento, outra ação tem sido desenvolvida em parceria com a câmara dos deputados, a partir da produção de curta metragem retratando a temática do feminicídio. Em 2020, uma escola da zona norte de Manaus ganhou o concurso, após retratar um caso real de uma aluna que era vítima de violência e compartilhou sua experiência. Acredita-se, dessa forma,

[...] que a Educação é um dos instrumentos de combate, prevenção e conscientização, e por assim ser, é imperativo disseminar uma Educação que reflita e debata com criticidade as desigualdades entre os homens e as mulheres, por meio dela podemos viabilizar a quebra de estereótipos culturais e formar sujeitos sociais críticos e dispostos a contestar os padrões historicamente estabelecidos e romper com o ciclo vicioso da violência contra a mulher, pondo em prática ações que visem o respeito às diferenças, pluralidade de ideias e o combate às desigualdades, sejam elas quais forem (Machado; Lima, 2021, p. 43).

Vale citar, ainda, um projeto realizado pelo Centro de Formação Padre Anchieta (Cepan), que comemorou os 350 anos da cidade de Manaus, o qual contou com a participação de aproximadamente 140 (cento e quarenta) escolas da rede pública do Estado, em Manaus. Uma das 07 (sete) escolas finalistas, pertencente à coordenadoria distrital de educação 04, zona oeste de Manaus, que retratou o feminicídio a partir do projeto "Monumento Tenente Roxana Bonessi", com o qual conquistou o primeiro lugar, dentre as escolas do Estado do Amazonas.

Essa prática pedagógica ganhou repercussão nos noticiários locais, os quais destacaram em suas manchetes a importância de se abordar questões como o feminicídio em atividades escolares. O site oficial da educação no Amazonas também destinou um espaço para divulgar a ação realizada de forma integrada e que gerou discussões significativas sobre a valorização e empoderamento feminino.

Machado e Lima (2021 p. 47) associam a violência contra a mulher a uma violação aos Direitos Humanos, por essa razão, "os meios quanto à prevenção e ao combate deste tipo de violência devem ser amplamente discutidos por todos os setores, tais como segurança pública, política, justiça, saúde e Educação, sendo esta última como um viés voltado para o desenvolvimento pleno".

Vale salientar que as ações relatadas, desenvolvidas pela Secretaria de Estado de Educação, aconteceram na capital amazonense, não havendo registros públicos, até o momento dessa escrita, sobre ações desenvolvidas nos municípios do interior do Estado, o que levanta um ponto de reflexão sobre o alcance das propostas da secretaria, ou seja, se as orientações sugeridas pelo Departamento de Planejamento e Políticas Educacionais têm chegado aos municípios do interior do Amazonas, os quais também precisam discutir temas relevantes, como a violência contra a mulher.

Ao pensar sobre a relevância da abordagem, no âmbito escolar, das questões em torno da violência de gênero, acredita-se que esse ainda é um caminho que deve ser percorrido, em busca de sensibilização acerca do enfrentamento e combate aos crescentes casos de feminicídio no Estado do Amazonas. Ferreira e Neves (2020) defendem que, apesar dos dispositivos legais existentes, como a Lei Maria da Penha e a Rede da Mulher, muitas mulheres continuam sendo violentadas no Estado do Amazonas e esses números sofreram um acréscimo significativo durante a pandemia de Covid-19, no ano de 2020.

Essa contextualização do quadro de violência no Amazonas sugere que a pandemia instaurou uma crise social sanitária, educacional e política, afetando as mulheres em diversos aspectos. (Ferreira \& Neves, 2020). Os autores destacam, inclusive, uma ação importante da Secretaria de Justiça, Direitos Humanos e Cidadania do Amazonas, intitulada "Mulher, seus direitos não estão em quarentena", com objetivo de fazer a divulgação das informações sobre os canais de denúncia, assim como das instituições de proteção e abrigo às mulheres em situação de violência. 
A partir da realidade exposta, é importante olhar atentamente as orientações sugeridas pela Secretaria de Estado de Educação do Amazonas, que tem desenvolvido através do seu Departamento de Políticas e Programas (DEPPE) algumas ações no âmbito das escolas estaduais da rede, com temáticas em torno dos casos de violência registrados no estado, pois,

[...] problematizar a violência contra a mulher dentro do contexto escolar é primordial para que os/as educandos/as possam refletir sobre o quão este tipo de violência está presente no cotidiano e o que, de fato, se pode fazer para modificar este panorama. É fundamental que a discussão sobre a violência contra a mulher e todos os conceitos que abarcam esta temática esteja evidenciados em todos os âmbitos do contexto escolar, do currículo ao material didático, pois como previsto na Lei Maria da Penha [...], a promoção e a realização de campanhas educativas de prevenção da violência doméstica e familiar contra a mulher, voltadas ao público escolar e à sociedade se fazem necessárias. (Machado \& Lima, 2021, p.51).

Ainda assim, ressalta-se que é preciso rever se essas ações estão alcançando os municípios do interior do Estado, visto que não se tem registros dessas abordagens nas coordenadorias regionais de educação. Caso essas ações sejam desenvolvidas, é preciso dar visibilidade aos trabalhos, a fim de mostrar o engajamento dos atores educacionais nessa luta, visto que no interior do Amazonas são registrados diversos casos de violência, como mostra o Atlas da Violência contra a mulher.

Machado e Lima (2021, p. 51) enfatizam que "a discussão desta temática por meio de metodologias, conteúdos e materiais didáticos que abarcam o contexto escolar e que evidenciem o combate à violência contra a mulher, são fundamentos basilares para sensibilizar cada educando/a sobre como este tema está presente e deve sim, ser combatido por todos/as". Entende-se que tais atividades deveriam ser trabalhadas de forma interdisciplinar e fazer parte do planejamento ordinário da escola, seja bimestral ou semestral, a fim de que todos os estudantes e professores possam se envolver nas discussões e reflexões sobre o tema e, desse modo, sensibilizar acerca do combate a qualquer tipo de violência contra a mulher.

\section{Considerações Finais}

Discorrer sobre as questões em torno da violência contra a mulher no contexto escolar tem se mostrado uma das ferramentas necessárias na luta pela sensibilização contra o feminicídio no Estado do Amazonas/Brasil, posto que a escola é uma instituição social de potencial alcance as mais variadas esferas da sociedade, podendo atuar de forma reflexiva e atuante. O papel da Secretaria Estadual de Educação é de relevância inegável, mas sua contribuição deve ser avaliada levando em consideração ao seu alcance, posto que o Estado do Amazonas possui uma dimensão geográfica elevada e muitos dos seus municípios acabam não sendo alcançados por algumas das ações propostas.

Pensando nisso, propõem-se uma investigação acerca da efetividade e alcance das ações propostas pela Seduc/Am, no âmbito das ações pedagógicas de sensibilização acerca do feminicídio, a fim de entender se os municípios do interior do estado são alcançados e de que forma acontecem essas práticas na comunidade escolar interiorana. Percebe-se, ainda, que os resultados das ações já realizadas podem e devem ser questionados e avaliados, pois ainda abordam a violência de forma opcional, ou seja, as escolas podem ou não inscrever práticas nos concursos, geralmente ficando a cargo do docente de artes trabalhar a propostas, por se tratarem de modalidades que envolvem teatro, música e redação, geralmente associadas à disciplina de Artes e, algumas vezes, língua portuguesa.

Desse modo, evidencia-se que o contexto de violência contra a mulher registrado no Estado do Amazonas não pode ser naturalizado, bem como os casos de feminicídios não devem ser apenas contabilizados, tratados como meros números em ascensão, é preciso que haja uma sensibilização coletiva, a fim de promover uma cultura de respeito, de valorização da mulher e das mudanças de papeis socialmente atribuídos a homens e mulheres, de modo que seja possível uma sociedade menos preconceituosa, sexista e violenta. 
Research, Society and Development, v. 11, n. 2, e12911224893, 2022

(CC BY 4.0) | ISSN 2525-3409 | DOI: http://dx.doi.org/10.33448/rsd-v11i2.24893

\section{Referências}

Almeida, D. N. (2019). Violência contra a Mulher (Lei Fácil Livro 1). Edições Câmara.

Antunes, I; Fávero; L. H. (2019). Os desafios do Estado no controle elou combate do feminicídio. Diálogos e Interfaces do Direito.

Batista, V. M. (2012). Questionar. IN. Fonseca, T. M; Nascimento, M. L. \& Maraschin, C. Org. Pesquisar na Diferença: um abecedário. Sulina.

Bianchini, A; Bazzo, M. Chakian, S. (2021). Crimes contra a mulher. Editora JusPodivm.

Brabo, T. S. Org. (2015). Mulheres, gênero e violência. Marília: Oficina Universitária. São Paulo: Cultura acadêmica.

Brasil (2006). Lei Maria da Penha. Lei n 11.340, de 07 de agosto de 2006.

Cerqueira, D. Org. (2020). Atlas da violência 2020. Ipea.

Costa, L. A. (2012). Contextualizar. IN. Fonseca, T. M; Nascimento, M. L. \& Maraschin, C. Org. Pesquisar na Diferença: um abecedário. Sulina.

Diagnóstico de gênero no Amazonas: políticas públicas e inclusão de mulheres (2020). Fundação Amazonas Sustentável. https://fasamazonia.org/publicacao/diagnostico-de-genero-no-amazonas-politicas-publicas-e-inclusao-de-mulheres/

Ferreira, B. O. \& Neves, A. L (2020). Reflexões sobre o feminicídio no contexto da pandemia de Covid-19 no Amazonas. Revista Espaço Acadêmico, n.224, p.47-57.

Figueiredo, P; Martins, Valéria (2020). O Feminismo Interseccional na articulação do saber acadêmico e da ação política: reflexões a partir da experiência de um coletivo feminista. Revista do Programa de Pós-Graduação em Relações Étnicas e Contemporaneidade.

Fonseca, T. M. G.; Nacimento, T. M. L \& Maraschin, C. Org. (2012). Pesquisar na diferença: um abecedário. Sulina.

Candau, V. M. (2020). Didática: revisitanto uma trajetória. In. Gandau, V. M.; Cruz, G. B; Fernandes, C. Org. (2020). Didática e fazeres-saberes pedagógias: diálogos, insurgências e políticas. Vozes.

Gastaldo, D. (2012). Pesquisador/a desconstruído/a e influente? Desafios da articulação teoria-metodologia nos estudos pós-críticos. In: Meyer, D. \& Paraíso, M. Org. (2012). Metodologia de Pesquisa Pós-Críticas em Educação. Mazza Edições.

Gomes, K.S. (2020). Violência contra a mulher e d 19. Revista Espaço Acadêmico.

Lemos, F. L. (2012). Pensar. IN. Fonseca, T. M; Nascimento, M. L. \& Maraschin, C. Org. Pesquisar na Diferença: um abecedário. Sulina.

Ludke, M. \& André, M. (2013). Pesquisa em educação: abordagens qualitativas. E.P.U.

Machado, F; Lima, M.S. (2021). A educação em direitos humanos no contexto escolar: perspectivas necessárias para a conscientização sobre a violência contra a mulher. In. Oliveira, M. Peixoto, R. (2021). Gênero, sexualidades e violência nos cotidianos escolares. Editora Bagai.

Meyer, D. \& Paraíso, M. Org. (2012). Metodologia de Pesquisa Pós-Críticas em Educação. Mazza Edições.

Oliveira, C. M; Cavalcante, L. L. (2021) \& Souza, R. (2021). Violência contra a mulher na cidade de Manaus e os reflexos da pandemia. Anais do V SERPINF e III. https://editora.pucrs.br.

Oliveira, M. Peixoto, R. (2021). Gênero, sexualidades e violência nos cotidianos escolares. Editora Bagai.

Peixoto, R; Pereira, T. C. B. (2021). A formação docente para o enfrentamento às violências de gênero e sexualidade na escola. In. Oliveira, M. Peixoto, R. (2021). Gênero, sexualidades e violência nos cotidianos escolares. Editora Bagai.

Rios, A. M. F. M; Magalhães, P. V. S; Telles, L. E. B. (2019). Revista Debates in Psychiatry. http://dx.doi.org/10.25118/2236-918X-9-2-4.

Zanella, A. V. (2012). Olhar. IN. Fonseca, T. M; Nascimento, M. L. \& Maraschin, C. Org. Pesquisar na Diferença: um abecedário. Sulina. 